\title{
A CASE STUDY ON EMPLOYEE MOTIVATION IN AN ORGANISATION
}

\author{
Dr. C K GOMATHY, Mr. S PAVAN KUMAR, Ms. PATHAPATI SRIVANI, Mr. SANNAPANENI ANAND \\ Sri Chandrasekharendra Saraswathi Viswa Mahavidyalaya, Kanchipuram
}

\begin{abstract}
Employee Motivation is about the commitment to doing something. Motivation plays an important role to meet the company's goals in an organization. In the context of a business, Motivation is said as "The will to work". The purpose of this study Employee Motivation is to examine the Motivation of employees. In every organization, an employee should be motivated well enough in order to perform their work well and also to feel job satisfaction. Motivated employees can lead to increased work productivity and allow to achieve higher levels of output.
\end{abstract}

Keywords: Employee Motivation, Employee Commitment, Employee's Work productivity.

\section{INTRODUCTION}

Inspiration is a theme that is broadly explored. Partially through the 20th century, the primary significant inspirational hypotheses emerged, in particular Maslow's order of necessities (1943), Herzberg's two-factor hypothesis (1959), and Vroom's anticipation hypothesis (1964). Those investigations zeroed in on inspiration overall and representative inspiration all the more explicitly. In the previous years, different meanings of inspiration were characterized, for example, Herzberg (1959) characterized worker inspiration once as playing out a business-related activity since you need to.

It regularly concurs that representative inspiration can be isolated into inborn and outward inspiration (Staw, 1976). Staw contends that one of the main endeavors to make that qualification was in Herzberg's Two-Factor Theory (1959). In any case, the conversation about characteristics and outward inspiration is more from last years (for example Amabile, 1993 and Deci and Ryan, 2000). Particularly significant is the conversation concerning how inherent and outward inspiration can add to workers exhibitions (Ramlall, 2008)

The connection between representative inspiration and occupation execution has been examined in the past(Vroom, 1964). Yet, high connections between's the two were not set up. Notwithstanding, later exploration reasoned that representative inspiration and occupation execution is without a doubt decidedly related (Petty et al., 1984). This relationship is concentrated in this postulation and the point is to give directors valuable data on how workers' exhibitions can be expanded by rousing them characteristically as well as extraneously.

Motivation assumes an imperative part in each circle of life. Worker achievement and accomplishments rely upon inspiration. The word inspiration is begotten from the Latin word "movere", and that means to move. Associations utilize workers to play out specific assignments, these representatives should be spurred to play out their undertakings well with the greatest usefulness. Yet again likewise to save representatives in an association for an extensive stretch of time, the worker inspiration process is liable for that.

Motivation can be intrinsic (emerging from inward factors) or outward (emerging from outside factors). 


\section{International Journal of Scientific Research in Engineering and Management (IJSREM)}

Inborn inspiration is characterized as doing an action for its intrinsic fulfillment. at the point when an individual is persuaded inherently, he/she is moved to represent the fun or challenge involved rather than as a result of outer items, strain, or rewards. Characteristic inspiration is significant for task diligence for owning an undertaking and for guaranteeing the investigation of arrangements.

Extrinsic motivation is reward-driven conduct. In extraneous inspiration, rewards or different impetuses like applause, distinction, or cash are utilized as inspiration for explicit exercises. Being paid to do a task is an illustration of extraneous inspiration.

\section{EMPLOYEE MOTIVATION}

It appears to be that motivation can be imagined in various ways; for example, numerous specialists attempted to form motivation yet completely proposed various approximations. Many explorations has been directed with regards to this subject and numerous speculations were planned that enormously affected and still impact authoritative conduct. For instance, Herzberg's hypothesis of inspiration (1959) is as yet utilized these days. As indicated by Staw (1976), Herzberg was one of the primary people who recognized natural and outward motivation. Also, that qualification could explain and hence assist with propelling workers. In this section, a few definitions will be referenced, along with a presentation of the hypotheses of Maslow (1943) and Herzberg (1959). However, more significantly, a detachment among inborn and outward inspiration is made.

\section{III.PROBLEM STATEMENT}

To what extent can the different types of employee motivation influence the performance of employees at the workplace?

\section{THE CONCEPT OF MOTIVATION}

The first question that arises is: "why do managers need to motivate employees?" (Herzberg, 1959). According to Smith (1994), it is because of the survival of the company. Amabile (1993) adds to this statement by arguing that it is important that managers and organizational leaders learn to understand and deal effectively with their employee's motivation; since motivated employees are necessary to let the organization be successful in the next century. She also argues that unmotivated employees are likely to expend little effort in their jobs, avoid the workplace as much as possible, exit the organization, and produce a low quality of work. In the case that employees are motivated; they help organizations survive in rapidly changing workplaces(Lindner, 1998). Lindner also argues that the most complex function of managers is to motivate employees; because what motivates employees changes constantly (Bowen and Radhakrishna,1991). In this paragraph, the different perspectives of motivation are described.

The term motivation arose in the early 1880s; before that time the term "will" was used by philosophers as well as social theorists when discussing effortful, directed, and motivated human behavior (Forgas, Williams, and Laham, 2005). According to them, motivation used to be considered as an entity that compelled one to action. Lately, various researchers proposed different definitions of motivation. Motivation has been 


\section{International Journal of Scientific Research in Engineering and Management (IJSREM)}

defined as the psychological process that gives behavior purpose and direction

(Kreitner, 1995); a predisposition to behave in a purposive manner to achieve specific, unmet needs(Buford, Bedeian, \& Lindner, 1995);

Internal drive to satisfy an unsatisfied need (Higgins, 1994); and the will to achieve (Bedeian,1993). Mitchell (1982) stresses that although there is some disagreement about the importance of different aspects in the definition of motivation, there is consensus about some underlying properties. Namely, that motivation is an individual phenomenon, it is described as being intentional, it is multifaceted and the purpose of motivational theories is to predict behavior. Mitchell (1982) also argues that motivation is concerned with action and the internal and external forces that influence one's choice of action. And that motivation is not the behavior itself, and it certainly is not performance. In relation to this, Mitchell (1982) proposes his own definition of motivation:

"Motivation becomes the degree to which an individual wants and chooses to engage in certain specified behaviors"

It is apparent that troughs need to persuade workers to acquire advantageous outcomes for the organization. Furthermore, it tends to be expressed that there is agreement about the realities that inspiration is an individual peculiarity, it is portrayed as being deliberate, it is complex, and that the purpose of persuasive hypotheses is to anticipate conduct. It appears to be that Herzberg and Maslow were among the first scientists at this theme and their speculations are as yet being utilized today.

\section{V.INTRINSIC AND EXTRINSIC MOTIVATION}

Motivation can be separated into intrinsic and extrinsic motivation. Amabile(1993) explains this as follows:

- Individuals are intrinsically motivated when they seek enjoyment, interest, the satisfaction of curiosity, self-expression, or personal challenge in the work.

- Individuals are extrinsically motivated when they engage in the work in order to obtain some goal that is apart from the work itself.

Deci describes extrinsic motivation as, money and verbal reinforcement, mediated outside of the person, whereas intrinsic motivation is mediated within the person. And a person is intrinsically motivated to perform an activity if there is no apparent reward except the activity itself or the feelings which result from the activity. Amabile argues that employees can be either intrinsically or extrinsically motivated or even both.

It seems that intrinsic and extrinsic motivators apply differently to persons. Vroom argues that some employees focus on intrinsic outcomes whereas others are focused on extrinsic outcomes. According to Story. Individuals high in intrinsic motivation seem to prefer challenging cognitive tasks and can self-regulate their behaviors, so offering rewards, setting external goals, or deadlines will do little for them unless they are also high in extrinsic motivation. For employees high in intrinsic motivation, emphasis could be placed on the engaging nature of the task and encouragement of self-set goals and deadlines. People high in growth need strength are most likely to be motivated by jobs with high skill variety, task identity, task significance, autonomy, and feedback. And people low in strength are relatively insensitive to these 


\section{International Journal of Scientific Research in Engineering and Management (IJSREM)}

factors according to them. This statement is supported by Furnhamet, they argue that introverts are more extrinsically motivated and extraverts more intrinsically motivated. However, it not only seems that persons are differently motivated but intrinsic and extrinsic motivation also has an effect on each other.

\section{VI.THE RELATIONSHIP BETWEEN INTRINSIC AND EXTRINSIC MOTIVATION}

The distinction between intrinsic and extrinsic motivation is evident, however researchers argue that intrinsic and extrinsic motivation also have an effect on each other. Deci (1972) claims that in some cases extrinsic motivators can decrease intrinsic motivation. He argues that if money is administered contingently, it decreases intrinsic motivation. But this event will not occur if the money is non-contingently distributed. Amabile (1993) reacts to this discussion by stating that although extrinsic motivation can work in opposition to intrinsic motivation, it can also have a reinforcing effect: "once the scaffolding of extrinsic motivation is taken care of, intrinsic motivation can lead to high levels of satisfaction and performance". She also states in her research that both intrinsic and extrinsic values can motivate employees to do their work, however intrinsic and extrinsic motivation can have very different effects on employees.

\section{CONCLUSION}

Motivation in the workplace is a broadly researched topic. Earlier research has been conducted by Maslow and Herzberg, who were pioneers at their subject. Lots of definitions have been composed.

The distinction between intrinsic and extrinsic motivation is also explained. Namely, individuals are intrinsically motivated when they seek enjoyment, interest, the satisfaction of curiosity, self-expression, or personal challenge in the work. And individuals are extrinsically motivated when they engage in the work in order to obtain some goal that is apart from the work itself. Both intrinsic and extrinsic motivators are important in motivating employees. It must be argued that managers must not focus on the most important factors solely. According to Herzberg, managers need to address all hygiene and motivator factors to motivate employees.

\section{VIII.REFERENCES}

1.Dr.C K Gomathy, Article: A Study on the recent Advancements in Online Surveying, International Journal of Emerging technologies and Innovative Research ( JETIR ) Volume 5 | Issue 11 | ISSN : 2349-5162, P.No:327-331, Nov-2018

2.Dr.C.K.Gomathy,C K Hemalatha, Article: A Study On Employee Safety And Health Management International Research Journal Of Engineering And Technology (Irjet)- Volume: 08 Issue: 04 | Apr 2021

3. Dr.C K Gomathy, Article: A Study on the Effect of Digital Literacy and information Management, IAETSD Journal For Advanced Research In Applied Sciences, Volume 7 Issue 3, P.No-51-57, ISSN NO: 2279-543X,Mar/2018

4. Dr.C K Gomathy, Article: An Effective Innovation Technology In Enhancing Teaching And Learning Of Knowledge Using Ict Methods, International Journal Of Contemporary Research In Computer Science And Technology (Ijcrcst) E-Issn: 2395-5325 Volume3, Issue 4,P.No-10-13, April '2017

5.Dr.C K Gomathy, Article: Supply chain-Impact of importance and Technology in Software Release Management, International Journal of Scientific Research in Computer Science Engineering and 
Information Technology ( IJSRCSEIT ) Volume 3 |

Issue 6 | ISSN : 2456-3307, P.No:1-4, July-2018

\section{AUTHOR'S PROFILE: -}

1)

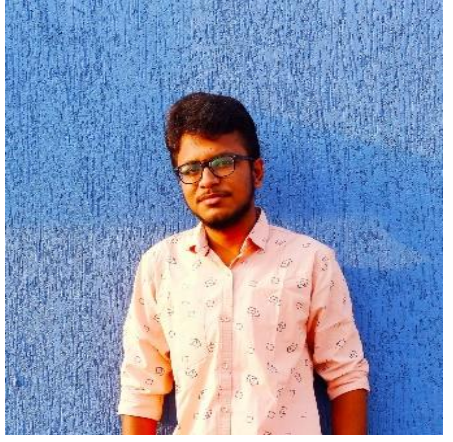

Mr. S Pavan Kumar, Student, B.E. Computer Science and Engineering, Sri Chandrasekharendra Saraswathi Viswa Mahavidyalaya, Enathur, Kanchipuram, India. His area of interest is in Software Development and Human Resources Development

2)

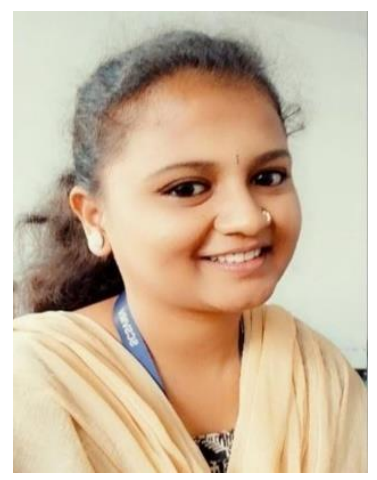

Ms. Pathapati Srivani, Student, B.E. Computer Science and Engineering, Sri Chandrasekharendra Saraswathi Viswa Mahavidyalaya, Enathur, Kanchipuram, India. Her area of interest is in Software Development and Human Resources Development.
3)

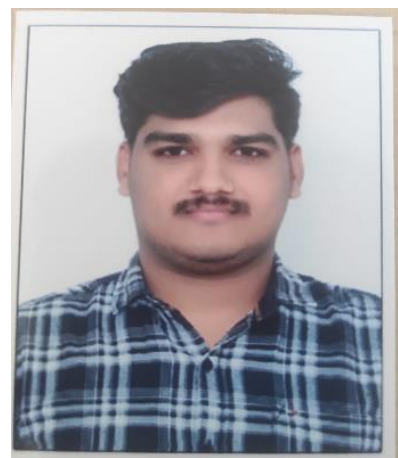

Mr. Sannapaneni Anand, Student, B.E Computer Science and Engineering, Sri Chandrasekharendra Saraswathi Viswa Mahavidyalaya, Enathur, Kanchipuram, India. His area of interest is in Software Development and Human Resources Development.

4)

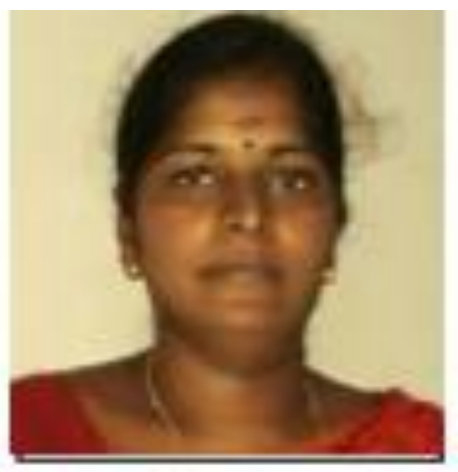

Dr. C.K. Gomathy is Assistant Professor in Computer Science and Engineering at Sri Chandrasekharendra Saraswathi Viswa Mahavidyalaya, Enathur, Kanchipuram, India. Her area of interest is in Software Engineering, Web Services, Knowledge Management and IOT. 